\title{
Sexual Function After a Proctectomy for the Treatment of Rectal Cancer
}

\author{
Young Wan Kim, Ik Yong Kim \\ Department of Surgery, Yonsei University Wonju College of Medicine, Wonju, Korea
}

\section{See Article on Page 210-215}

The incidence of anal-sphincter-preservation surgery for the treatment of rectal cancer has increased since the popularization of a total mesorectal excision with pelvic autonomic nerve preservation based on a better understanding of the pelvic anatomy [1]. In recent years, both colorectal surgeons and cancer patients have given increased attention to the quality of life after rectal-cancer surgery [2]. A well-preserved function is directly related to better quality of life. Functional outcomes after rectal-cancer surgery include voiding, sexual function, and defecation [3]. However, sexual function has often been neglected in the conservative societies such as that in Korea. In this regard, Attaallah et al. [4] presented a timely paper in this issue of the Annals of Coloproctology. The authors evaluated sexual dysfunction after rectal-cancer surgery by using a questionnaire and found that postoperative sexual dysfunctions were common and that women were at high risk for sexual dysfunction. This study is valuable in that sexual function in men and women has rarely been studied. However, inherent limitations, such as small sample size and a cross-sectional study, still exist.

In a recent review by Ho et al. [5], deterioration of sexual function after rectal-cancer surgery was observed in $23 \%$ to $69 \%$ of men and $19 \%$ to $62 \%$ of women. However, potential contributing factors (either treatment- or patient-related) to, the duration of, and the treatment for sexual dysfunction are still under debate. Standardized and validated evaluation tools are lacking. Previous studies used questionnaire surveys, but various types of question-

Correspondence to: Ik Yong Kim, M.D.

Department of Surgery, Yonsei University Wonju College of Medicine,

20 Ilsan-ro, Wonju 220-701, Korea

Tel: +82-33-741-0573, Fax: +82-33-744-6604

E-mail: iykim@yonsei.ac.kr

(C) 2014 The Korean Society of Coloproctology

This is an open-access article distributed under the terms of the Creative Commons Attribution NonCommercial License (http://creativecommons.org/licenses/by-nc/3.0) which permits unrestricted noncommercial use, distribution, and reproduction in any medium, provided the original work is properly cited. naires were used. In the near future, studies to evaluate the functional outcome data for Korean rectal-cancer patients through multicenter studies may be worthwhile.

\section{REFERENCES}

1. Kim NK, Min BS, Kim JS, Hur H, Lee KY, Sohn SK, et al. Oncologic outcomes and safety after tumor-specific mesorectal excision for resectable rectal cancer: a single institution's experience with 1,276 patients with rectal cancer. J Korean Soc Coloproctol 2008;24:121-33.

2. Min HS, Kim JY. Health-related quality of life of patients with rectal cancer. J Korean Soc Coloproctol 2009;25:100-6.

3. Won SL, Kim IY, Sung SH, Kim DS. Functional and oncologic outcome of coloanal anastomosis in low lying rectal cancer. J Korean Soc Coloproctol 2005;21:419-25.

4. Attaallah W, Ertekin C, Tinay I, Yegen C. High rate of sexual dysfunction following surgery for rectal cancer. Ann Coloproctol 2014; 30:210-5.

5. Ho VP, Lee Y, Stein SL, Temple LK. Sexual function after treatment for rectal cancer: a review. Dis Colon Rectum 2011;54:11325 . 